\title{
Contabilidade
}

\section{ANÁLISE INSTITUCIONAL DA INFLUÊNCIA DO FMI SOBRE A CONVERGÊNCIA ÀS IPSAS PELO BRASIL}

\begin{tabular}{|c|c|}
\hline Nome & Luiza Raad \\
\hline Instituição/Afiliação & Universidade de Brasília - UnB \\
\hline País & Brasil \\
\hline Nome & Tiago Mota dos Santos \\
\hline URL & https://orcid.org/0000-0001-7502-8866 \\
\hline Instituição/Afiliação & Universidade de Brasília - UnB \\
\hline País & Brasil \\
\hline Nome & Eduardo Tadeu Vieira \\
\hline Instituição/Afiliação & Universidade de Brasília - UnB \\
\hline País & Brasil \\
\hline Nome & Jorge Katsumi Niyama \\
\hline Instituição/Afiliação & Universidade de Brasília - UnB \\
\hline País & Brasil \\
\hline
\end{tabular}

\section{RESUMO}

A New Institucional Sociology traz à luz a pressão externa que as instituições sofrem, como isso as influencia e também como a busca por legitimação pode levar os agentes internos a se afastarem da decisão racional. Esta abordagem elucida o processo de isomorfismo; destaca-se o coercitivo que seria originado de pressões formais exercidas por organizações com influência política sobre a outra. Procuramos responder qual foi a influência do FMI no Brasil para a adoção das IPSAS, dado que há possibilidade de o Brasil retornar à posição de devedor no Fundo. Verificou-se que na ótica do regulador o FMI não exerce nenhuma pressão, formal, para a convergência, entretanto, há uma pressão coercitiva informal para que o Brasil adotasse o regime de competência e as IPSAS como um todo.

Palavras Chave: Processo de Convergência; IPSAS; FMI; Teoria Institucional

\begin{abstract}
New Institutional Sociology brings to light the external pressure that institutions suffer, how it influences them and also how the search for legitimacy can lead internal agents to move away from rational decision. This approach elucidates the isomorphism process; it stands out the coercive that would be originated from formal pressures exerted by organizations with political influence over the other. We seek to answer what was the IMF's influence in Brazil for the adoption of IPSAS, given that there is a possibility that Brazil will return to the position of debtor in the Fund. It was found that, from the regulator's point of view, the IMF exerts no formal pressure for convergence, however, there is an informal coercive pressure for Brazil to adopt the accrual regime and the IPSAS as a whole.
\end{abstract}

Key words: Convergence Process; IPSAS; IMF; Institutional Theory 


\section{Revista \\ UNEMAT de \\ Contabilidade}

v. 9 , n. 17,2020

\section{INTRODUÇÃO}

É possível observar que, no contexto de globalização, os Estados vêm buscando também harmonizar a forma de apresentarem a informação contábil e os conceitos por trás dela; Lima (2017) aponta que há uma tendência à adoção das IPSAS (International Public Sector Accounting Standards) - seja pela falta de outra norma de padrão internacional ou pela crença de que essas serão úteis para a melhoria da qualidade da informação contábil do setor público.

A teoria neo-institucional diz que as instituições tomam decisões não só por razões econômicas, mas também em busca de legitimidade (Oyadomari et. al, 2008). DiMaggio e Powell (1983) apresentam que as organizações de um mesmo setor tendem a aplicar práticas semelhantes em busca de legitimidade - ao que chamam de isomorfismo; estes autores elucidam que a aplicação de mecanismos isomórficos institucionais não necessariamente levará a uma maior eficiência para organização; mas que a sociedade e outras organizações podem gerar o isomorfismo coercitivo a partir de pressão formal ou informal. Além disso, apontam que mudanças estruturais podem ter a causa no isomorfismo normativo (por profissionais da área) ou no isomorfismo mimético (reprodução de boas práticas em contexto de incertezas).

Lima (2017) verificou que o Conselho Federal de Contabilidade (CFC) e a Secretária do Tesouro Nacional (STN) possuem um papel predominante neste processo, mas com pressupostos diferentes: o primeiro busca atender à necessidade dos profissionais da contabilidade e o segundo, padronizar e consolidar a contabilidade pública - recebendo influência do FMI sobre a elaboração de estatísticas fiscais do país.

Em 1998, o Brasil inicia a reforma da contabilidade pública por uma informação consolidada a nível subnacional sob o Special Data Dissemination Standard (SDDS - Padrão Especial de Disseminação de Dados) e em 2000 promulga a Lei de Responsabilidade Fiscal outra demanda do FMI (ALVES, PELIANO E COIMBRA, 1998).

Para cumprir com sua missão, definida na Conferência de Bretton Woods em 1944, o FMI concede a seus membros recurso financeiro necessário para equilibrar a balança de pagamentos e aponta soluções econômicas que devem ser aplicadas em contrapartida ao empréstimo (ITAMARATY, n.d.). O Brasil por muitos anos se viu dependente dos recursos do Fundo para equilibrar suas contas - apesar de não aplicar algumas medidas acordadas, consideradas ortodoxas -, até que em 2010 passa à posição de credor e a aplicar esforços em 


\section{Revista \\ UNEMAT de \\ Contabilidade}

v. 9, n. 17,2020

conjunto com outros países em desenvolvimento para ter maior influência nas tomadas de decisão desta instituição (Almeida, 2014).

Neste estudo busca-se responder: qual foi a influência do FMI para que o Brasil adotasse as IPSAS? O objetivo desta pesquisa é encontrar, por meio de uma pesquisa bibliográfica, evidências da pressão coercitiva do Fundo Monetário Internacional (agente de pressão externa) sobre o processo de conversão às IPSAS buscando contribuir na formação da análise crítica desse processo.

Este estudo está dividido em seis partes, sendo a primeira essa introdução; a segunda trata do referencial teórico dividido em: teoria institucional e as normas IPSAS; a terceira e o processo de convergência às IPSAS no Brasil; na quarta parte apresenta-se o FMI; na quinta demonstra-se a relação do Brasil com o FMI; fechando com as conclusões dessa.

\section{TEORIA INSTITUCIONAL}

Segundo Scott \& Meyer (1994) e Mintzberg et al. (2000) pode ser conceituada como a que administra impressões, procurando explicações sobre a estrutura e o funcionamento das instituições numa realidade social, nesse panorama, as instituições são vistas como entes que atuam em função das regras, dos procedimentos, crenças e valores predominantes em um determinado contexto.

Atuar em função de regras, procedimentos, crenças e valores predominantes em um determinado contexto nos remete ao sustentado por Vázquez (1992), ele preceitua que os grupos sociais "tem a pretensão de que seus princípios e suas normas tenham validade universal". Sendo assim, podemos considerar que os normatizadores internacionais da contabilidade (o International Accounting Standards Board (IASB) e o International Public Sector Accounting Standards Board (IPSASB)) são grupos sociais que buscam a edição de normas contábeis com validade universal.

A contabilidade pode ser entendida como instituição dentro de uma organização, influenciando - por vezes impondo - o ambiente interno ao mesmo tempo que sofre influência do ambiente e de atores externos e das rotinas e hábitos dos atores internos (Guerreiro; Frezatti; Casado, 2006; Guarido Filho; Costa, 2012). 


\section{Revista \\ UNEMAT de \\ Contabilidade}

v. 9, n. 17,2020

Sob a ótica da psicologia, Guerreiro, Frezatti e Casado (2006) apontam que a instituição é moldada por rotinas que guiam o comportamento de um grupo e essas construídas por hábitos formalizados, institucionalizados e orientados por regras da organização. Todavia há de se destacar que "definir instituições como hábitos nos levaria ao equívoco de presumir que instituições não mais existem se os hábitos aos quais estão associadas forem interrompidos" (HODGSON, 2006).

Segundo Selznick (1972), um dos precursores da teoria institucional, a instituição seria um instrumento técnico que guiaria as energias humanas para um fim específico. Sob essa perspectiva Lima (2017) diferencia instituição de organização, sendo a primeira "adaptável e fruto de pressões e necessidades sociais", enquanto a segunda seria um "sistema formal com regras e objetivos".

Instituições podem ser definidas como "sistemas de regras sociais estabelecidas e prevalecentes que estruturam as interações sociais. Linguagem; dinheiro; lei; sistemas de pesos e medidas; e empresas (e outras organizações) são, assim, todos instituições. (...) Elas dependem dos pensamentos e atividades dos indivíduos, mas não são redutíveis a esses" (HODGSON, 2006). Para Peci (2006) instituições são "estudo da sociedade em ação, ainda que de uma ação que transcorre nos limites de formas sociais solidamente estabelecidas".

Ao contrário, segundo Hodgson (2006), as organizações são um tipo especial de instituição que envolve “(a) critério para estabelecer seus limites e para distinguir seus membros de não-membros, (b) princípios de soberania sobre quem está no comando, e (c) cadeias de comando delineando responsabilidades dentro da organização".

A Teoria Institucional, e suas vertentes, busca entender como as organizações procuram legitimar-se em seu ambiente, essa busca justifica a existência de estruturas organizacionais análogas e de organizações que adotam práticas de gestão similares (SCHULTZ, 2016).

A partir desta abordagem, que fornece subsídios para a análise das pressões institucionais sofridas por uma organização, diversos autores institucionalistas segundo Daft (2014, p. 187), lembram que "as organizações adotam estruturas e processos para agradar às pessoas de fora e essas atividades acabam por assumir um status de regras nas organizações”.

Levando em consideração essa premissa ao aderir o processo de convergência às normas internacionais as normas produzidas pelo organismo normatizador passam a ter status de regras, 


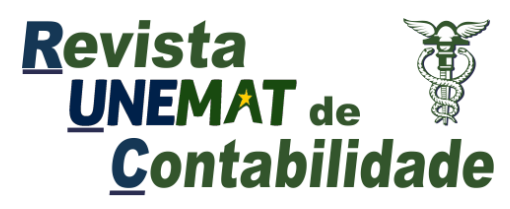

v. 9 , n. 17,2020

no Brasil o início do processo se deu pela mera tradução das normas sem antes verificar quais seriam as implicações locais dessa adoção.

Por fim, Scott \& Meyer (1994) indica a existência de várias vertentes da Teoria Institucional, sendo as mais pesquisadas na área contábil: a nova economia institucional, a velha economia institucional e a nova sociologia institucional.

De acordo com Burns e Scapens (2000), a teoria institucional é estudada em três frentes: (i) Velha Economia Institucional (OIE - Old Institutional Economics); (i) Nova Economia Institucional (NIE - New Institutional Economics); e (iii) Nova Sociologia Institucional (NIS New Institutional Sociology).

A Velha Economia Institucional tem sua origem na tradição institucionalista americana predominante entre o final do século XVIII para o século XIX e depois dos anos 1930 entra em declínio (Simões; Rodrigues, 2012). A OIE se opõe a teoria neoclássica - que por sua vez tinha como objeto principal a busca racional por eficiência dos tomadores decisões - e passa a centrar a análise na instituição (Guerreiro; Frezatti; Casado, 2006, Barbosa Neto; Colauto, 2010).

“A VEI [Velha Economia Institucional] procura entender como os hábitos e as regras são transmitidos, replicados e como estruturam a atividade econômica. (...) Enquanto que a Nova Economia Institucional (NEI) assume que os hábitos são a consequência de escolhas racionais, a VEI assume que as escolhas racionais são explicadas pelos hábitos" (Simões; Rodrigues, 2012). Já Peci (2006) enxerga uma consonância entre o novo e o velho institucionalismo: o foco nas relações da organização com o ambiente externo, ao invés da ação do tomador de decisão.

A NIE centraliza-se em processos de mudanças, especialmente as de cunho isomórfico e estudos com essa perspectiva acabam por superestimar aspectos como o mimetismo organizacional (Peci, 2006). Segundo Reis (2008), a Nova Economia Institucional centralizase nas transações e em seus respectivos custos. A preocupação seria em compreender por que tais custos variam entre as organizações (CONCEIÇÃO, 2002)

Simões e Rodrigues (2012) concluíram em seu estudo que a OIE, entre outras limitações, negligencia a influência das instituições externas sobre as práticas e a mudança da contabilidade. Enquanto o campo de análise da NIE são a ênfase nos aspectos internos das empresas; as noções de mercados e hierarquias; e as falhas de mercado (Conceição, 2002). Portanto decidiu-se não utilizar essas duas vertentes da Teoria Institucional para esta pesquisa. 


\section{Revista \\ UNEMAT de \\ Contabilidade}

v. 9 , n. 17,2020

A Teoria Neo-Institucional (NIS) é caracterizada como uma abordagem sociológica que explica que as organizações adotam determinadas práticas como formas de legitimação, e não prioritariamente por razões econômicas (Oyadomari et. al, 2008; Mósca, 2006). O conceito de legitimidade está associado à necessidade que a organização tem de ser aceita e ter credibilidade social - essencial para sua existência e manutenção (Lima, 2017). As instituições públicas têm maior necessidade de terem a legitimidade de sua informação contábil reconhecida (Carpenter e Feroz 1992), uma vez que traduzem as decisões tomadas (Dias Filho; Machado, 2012), e que destas não resulta um lucro líquido, para que se possa avaliar os seus resultados.

O conceito de cultura organizacional de Schein (1992) nos permite também compreender por que organizações de um mesmo campo convergem em suas práticas: a cultura organizacional é construída a partir de soluções para problemas de adaptações e para a integração interna e dessas se definem pressupostos básicos. "Isomorfismo ou homogeneização (...) não deriva de reprodução irrefletida, mas de regularidade proveniente da aceitação de determinada ação, que justamente em função de ser interpretada como legítima, é reproduzida pelos agentes na prática social e se consolida como padrão institucionalizado, por ser consentida como escolha desejável e viável” (MACHADO-DA-SILVA; FONSECA; CRUBELLATE, 2005).

DiMaggio e Powell (1983) diferenciam os mecanismos isomórficos em: i) isomorfismo mimético (em respostas às incertezas, as organizações buscam imitar aquelas do mesmo campo de atuação que se mostram bem-sucedidas); ii) isomorfismo coercitivo (originado de pressões formais ou informais exercidas por uma - ou mais - organização com influência política sobre a outra, ou também pela expectativa da sociedade); e iii) isomorfismo normativo (decorrente da pressão dos profissionais da área - seja por meio da Academia ou instituições de capacitação profissional, que promovem o desenvolvimento de normas organizacionais, seja pelas associações profissionais, que, por sua vez, exercem influência na criação de regras que normatizam o comportamento organizacional e profissional).

Menezes Júnior et al. (2016) verificaram, sob a perspectiva institucionalista, à luz do isomorfismo mimético, a aderência das IPSAS ao padrão internacional de contabilidade para o Setor Privado (IFRS, produzido pelo IASB), uma vez que essas, reservadas as especificidades do setor público, foram elaboradas com base neste, compartilhando princípios contábeis e copiando-lhe seus textos. 


\section{Revista \\ UNEMAT de \\ Contabilidade}

v. 9 , n. 17,2020

Para Sasso (2017), a Teoria Institucional é adequada para se analisar o processo de convergência às IPSAS justamente porque essa verifica a pressão externa sobre a organização e como as "organizações interagem para estar em conformidade com o processo de institucionalização e obter, por conseguinte, legitimidade, como um de seus benefícios". A autora verificou - unindo aquela com a teoria da dependência de recursos - como os Estados do Rio de Janeiro, São Paulo e Minas Gerais reagiram ao processo de convergência, identificando os fatores que condicionam e enfraquecem a conformidade às mudanças contábeis, reconhecendo-as como um processo de mudança institucional.

À luz da Teoria Institucional, Borges (2014) conclui que o processo de convergência não se finda na mudança legal e que a própria encontra obstáculos de recepção em vista da cultura organizacional de cada ente do governo; pôde verificar, inclusive, que a imposição sem um preparo para o ambiente institucional "tende a dificultar e, no extremo, inviabilizar" a adoção da nova rotina contábil.

\section{IPSAS}

Segundo Chan (2010) um sistema contábil governamental de qualidade é um instrumento para que se aprimore a gestão das finanças públicas, mas em vista do significativo custo (financeiro e de oportunidade) de implementação é necessário que os países recebam incentivo econômico para realizá-la. "A adoção das IPSAS pelos diversos países tem sido crescente, especialmente devido às recomendações para a implementação de competência nos governos realizadas por organismos internacionais, tais como o Banco Mundial e o FMI" (LIMA, 2017).

Macêdo et. al (2010) afirmam que a contabilidade governamental se apoia em dois conceitos: accountability e true and fair view. O segundo, se traduz na visão verdadeira e apropriada sobre o patrimônio, enquanto o primeiro - não tendo uma correspondência exata na língua portuguesa - poderia ser traduzido, de forma resumida, por responsabilidade objetiva, transparência e prestação de contas (Macêdo et al., 2010; TCU, n.d.; Nakagawa, 2007). 
As IPSAS seriam "um mecanismo de coordenação para reduzir os custos de accountability" (Chan, 2010) e essa seria a possível razão pela qual os organismos internacionais têm apoiado o processo de adoção das IPSAS (Lima, 2017).

As Normas Internacionais Aplicadas ao Setor Público (IPSAS, do inglês International Public Sector Accounting Standards) foram criadas pelo esforço do International Public Sector Accounting Standards Board (IPSASB), um comitê do International Federation of Accountants (IFAC). O IFAC é uma organização internacional de profissionais contábeis que objetiva defender o interesse comum de que sejam produzidas informações contábeis de alta qualidade sob um padrão internacional; contribuindo para o desenvolvimento de economias fortes (IFAC, 2013).

Em 2003, o Comitê do Setor Público (PSC) do IFAC - atual IPSASB - reuniu-se com organizações de relevância internacional que já tinham intenção de produzir um padrão contábil - entre elas o Fundo Monetário Internacional, a Organização para a Cooperação e Desenvolvimento Econômico (OCDE) e o Tesouro do Reino Unido. Criou-se depois o Task Force on the Harmonization of the Public Sector Accounting (TFHPSA), que, sob a liderança do FMI, busca maneiras de se reduzir as diferenças entre os relatórios contábeis e faz recomendações ao IPSASB (IFAC, 2013).

O IPSASB desenvolve normas e diretrizes para a contabilidade aplicada ao setor público; seu objetivo atualmente é expandir e divulgar as IPSAS e a adoção do regime por competência na contabilidade pública dos países, com a intenção de que sejam aprimorados a gestão e conhecimento das finanças públicas (IPSASB, 2019). Existem dois métodos de convergência às IPSAS: direto e indireto. O primeiro faz menção direta aos padrões internacionais, enquanto o segundo - adotado pelo Brasil - permite alterações no texto da norma para se adequar à realidade jurídica e institucional do país, sob o risco de incorrer em divergências ao Padrão (Girotto, 2019).

\section{O PROCESSO DE CONVERGÊNCIA NO BRASIL}


No Brasil, em termo cronológico, tem-se: a partir de 2008, o Conselho Federal de Contabilidade (CFC) emitindo normas para a contabilidade pública alinhadas às normas internacionais. No âmbito da regulação brasileira segundo Figueiredo (2017):

[...] Ministério da Fazenda do Brasil publicou a Portaria $n^{\circ}$ 184, de 25 de agosto de 2008, dispondo sobre a intenção de convergir as regras contábeis voltadas para entes públicos de acordo com as Normas Internacionais de Contabilidade Aplicadas ao Setor Público - IPSAS, emitidas pela IFAC através do seu comitê, o IPSASB (Figueiredo, 2017, p. 18).

Ao exercer seu papel o regulador brasileiro justifica a adesão do Brasil ao processo de convergência primeiro por conta do cenário econômico mundial e por causa da globalização; em segundo lugar por conta do estágio econômico alcançado pelo Brasil e somente em terceiro lugar cita a transparência e a comparabilidade como atributos de qualidade das demonstrações financeiras convergidas (Fazenda, 2008).

Em 2015, o CFC cria o Grupo Assessor das Normas Brasileiras de Contabilidade Aplicadas ao Setor Público (GA - Área Pública) para que houvesse de fato a convergência às IPSAS. Em outubro de 2016, o Conselho publica no Diário Oficial da União (DOU) a Estrutura Conceitual que passa a ser a base para as normas brasileiras de contabilidade pública.

Foi definido com a Secretaria do Tesouro Nacional, os Tribunais de Conta dos Estados (TCEs), o Tribunal de Conta da União (TCU), a academia e representantes dos Estados um cronograma -desafiador- para que até 2021 todas as normas estivessem convergidas (CFC, 2016).

O Manual de Contabilidade Aplicado ao Setor Público, produzido pela STN, em sua $8^{\circ}$ versão - válido para os exercícios de 2019, 2020 e 2021 (STN, 2017) - traz também o desenvolvimento histórico até as circunstâncias atuais de adoção das IPSAS: a Lei n 4320/1964 definiu regras para o controle das finanças públicas, estabeleceu o orçamento como objeto principal da contabilidade - por conseguinte as normas subsequentes foram elaboradas sob o enfoque orçamentário e não patrimonial.

Segundo Chan (2010), servidores públicos e a sociedade em geral ainda viam o orçamento como "principal documento financeiro governamental". Em 2000, foi sancionada a LRF - no Manual destaca-se desta a obrigação de ser realizada a consolidação nacional das 
contas públicas. À Secretaria do Tesouro Nacional (STN) foi dada a competência para se fazer cumprir tal obrigação.

Na ausência do conselho de gestão fiscal previsto no Art. 67 da LRF, a STN passa à condição de órgão central do Sistema de Contabilidade Federal (inciso I do art. $6^{\circ}$ do Decreto n 6.976/2009) também cria o Grupo Técnico de Padronização de Procedimentos Contábeis (GTCON) (Brasil, 2014).

De caráter técnico e consultivo, o GTCON subsidia a Secretaria com diagnósticos e estudos sobre padronização da contabilidade da União, Estado e Municípios, sob uma mesma base conceitual e práticas contábeis; plano de contas; e classificação orçamentária de receitas e despesas nas três esferas de governo. A Academia está representada no GTCON pela Fundação Instituto de Pesquisas Contábeis, Atuariais e Financeiras (FIPECAFI FEA/USP).

A Portaria STN n ${ }^{\circ}$ 548/2015 define o Plano de Implantação das normas convergidas, estabelecendo que até 2024 as três esferas de governo já as tenham adotado integralmente em sua contabilidade (IBRACON, 2017).

Vale apontar que, em entrevista, o representante do Brasil no IPSASB, Leonardo Nascimento, afirma “o IPSASB entende que não há justificativa para se exigir a aplicação do conjunto completo das IPSAS para pequenas províncias ou, no caso brasileiro, pequenos municípios", uma vez que o custo-benefício para a transparência e processos decisórios dessas entidades seria questionável em vista do alto grau de investimento que seria necessário para implantá-las (GIROTTO, 2017).

\section{O FUNDO MONETÁRIO INTERNACIONAL (FMI)}

O FMI é uma agência da Organização das Nações Unidas (ONU) criada em julho de 1944 na Conferência de Bretton Woods. Ele tem as missões de promover a cooperação monetária internacional; garantir a estabilidade financeira dos países membros, inclusive disponibilizando recursos para ajudar no equilíbrio da balança de pagamentos; além de promover alto nível de emprego e o crescimento econômico sustentável e reduzir a pobreza em todo o mundo. (ONU, n. d.; ITAMARATY, n.d.) 


\section{Revista \\ UNEMAT de \\ Contabilidade}

v. 9 , n. 17,2020

Para tanto age de três formas: monitoramento do sistema monetário internacional; empréstimos aos países-membros; programa de capacitação, oferecendo assistência técnica e treinamento. Periodicamente o FMI faz recomendações para os países membros a partir de pesquisas, levantamentos estatísticos e previsões econômicas globais e regionais realizadas pela agência. Os países que desejam captar recursos a fim de equilibrar seus pagamentos devem cumprir com os requisitos acordados numa negociação com o Fundo (ITAMARATY, n.d.).

O Fundo Monetário Internacional entende que se um país que não consegue cumprir com seus compromissos internos, ou internacionais, pode provocar um grande desequilíbrio no sistema financeiro internacional; tendo sido criado para mantê-lo estável, concede recursos suficientes para que o país possa reequilibrar sua balança de pagamento ao mesmo tempo que implementa reformas econômicas para restabelecer sua independência financeira (FMI, n.d.).

Diferente de outras instituições financeiras internacionais (como o BM), o FMI não financia projetos. Todavia, ao longo de sua história, já concedeu empréstimos para equilibrar a balança de pagamentos em casos de desastres naturais; situação pós-conflito; redução de pobreza e desenvolvimento econômico; reestruturação da dívida soberana; crises bancárias e cambiais; etc. (FMI, n.d.).

Hoje, o empréstimo do FMI serve três propósitos: i) suavizar efeitos de choques econômicos e evitar a inadimplência soberana (assim, evitando um efeito em cascata para a economia de outros países); ii) os programas de reforma econômica que o FMI propõe em troca do recurso financeiro podem servir para dar credibilidade e legitimar as políticas de ajustes econômicos que o país está realizando e, assim, ajudá-lo a ter acesso a outras fontes de financiamento; iii) ajudar a prevenir crises econômicas no sistema internacional, evitando que se propaguem os efeitos de crises nacionais (FMI, n.d.).

Para tomar um empréstimo com o Fundo, o país precisa entrar em acordo com a instituição sobre uma política econômica a ser aplicada - o Fundo se preocupa em propor uma solução eficaz para a realidade de cada um de seus membros - e então é preciso que o governo escreva uma "carta de intenções" ao diretor-geral da instituição comprometendo-se a aplicar o foi proposto. A proposição de política econômica pode ser, dentre outras, o estabelecimento de metas de reservas fiscais ou cambiais (FMI, n.d.).

\section{A RELAÇÃO ENTRE O BRASIL E O FMI}




\section{Revista

Uma vez estabelecidas as condições, em geral, o FMI libera sucessivas parcelas do valor definido enquanto o país devedor executa o programa econômico para restabelecer-se (FMI, n.d.). No governo Juscelino Kubitschek, o Brasil rompe o acordo feito, para não ver seus gastos controlados na fase de construção de sua nova capital (Almeida, 2014; Biderman, Cozac, Rego, 1996). Com a posse de Jânio Quadros, o governo retoma a negociação com o FMI e este aprova o plano de estabilização econômica, prorroga a dívida brasileira e concede mais US\$ 2 bilhões (BIDERMAN ET. AL, 1996).

Nos governos de Castelo Branco, Costa e Silva e até os primeiros anos do governo Médice, o país realizou acordos ano a ano com o FMI. A partir da segunda metade de 1982, após duas crises do petróleo quase consecutivas, os países latino-americanos passaram por uma onda de inadimplências. O diretor-gerente do FMI teve de obrigar os bancos comerciais a prosseguir emprestando para esses países, renegociando as amortizações devidas, para que não houvesse uma paralisação virtual do sistema de créditos comerciais, estando a instituição preparada apenas para cobrir desequilíbrios no balanço de pagamentos - e não para cobrir por longo período dívidas externas. A dívida externa brasileira aumentou significativamente, estando a frente do México, Argentina e Venezuela (ALMEIDA, 2014).

"A inadequação dos mecanismos institucionais para o encaminhamento adequado do problema da dívida externa era patente. Por um lado, os bancos privados tinham sido extremamente irresponsáveis ao conceder empréstimos sobre empréstimos aos governos dos países em desenvolvimento, na suposição absurdamente anti-histórica de que Estados soberanos não vão à bancarrota e não declaram moratória. Eles estavam esperando que o governo dos Estados Unidos e o próprio FMI garantisse pelo menos o pagamento dos juros por parte dos países devedores, algo que esteve sob risco em diversas ocasiões.” (ALMEIDA, 2007, p. 77)

Berti (1999) aponta uma assimetria informacional existente entre os credores internacionais e o Brasil: o país argumentava possuir elevadas reservas, desconsiderando as dívidas externas de curto prazo e ainda o Banco Central incluíra no cálculo de suas reservas alguns ativos "de liquidez extremamente discutíveis: os créditos incobráveis junto à Polônia e 


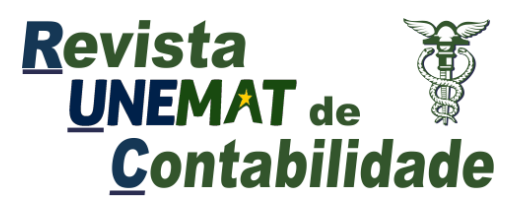

v. 9 , n. 17,2020

as obrigações de países latino-americanos e africanos com o Brasil, que com a crise financeira dificilmente seriam honrados".

Num contexto de grande e contínua elevação das taxas de juros internacionais; queda do preço de produtos primário; somados à segunda crise do petróleo, a década de 1980 foi marcada por renegociações dos acordos feitos com a agência, pelo descumprimento de metas estabelecidas e por valores, pois, travados. O Brasil declara moratória em 1987. E novamente em 1989 (Almeida, 2014; Berti, 1999). "E os inúmeros planos de estabilização que o FMI aconselhou ao Brasil, todos rigorosamente equivocados!" afirma Bresser em entrevista (BIDERMAN ET. AL, 1996, p.180).

O economista à frente do Ministério da Fazenda, Luiz Carlos Bresser Pereira, apresentou aos bancos privados, em 1987, a proposta de empréstimos a juros zero, com bônus voluntários pagos a cada parcela de amortização - preocupando-se mais em reaver a credibilidade com os credores internacionais que de fato diminuir a dívida externa. $\mathrm{O}$ Tesouro norte-americano recusou a proposta. No entanto, dois anos mais tarde, o então secretário do Tesouro estadunidense, aos moldes da sugestão de Bresser, propõe o Plano Brady, reconhecendo a dificuldade dos países super-endividados em pagar suas dívidas (ALMEIDA, 2014).

Sobre o Plano antecedente ao Plano Real, o Plano Verão, Bresser (1989) aponta de forma alarmante que o "déficit público aumentou ao invés de diminuir, devido à ortodoxia equivocada da política monetária. O crédito do Estado diminuiu e a credibilidade do governo está mais baixa do que nunca." O autor ainda destaca a intensa fuga de capitais em vista do "fantasma do deságio" que pairava sobre a dívida interna; e também o medo que permeava o mercado sobre um novo período hiper inflacionário.

O Brasil se via numa fase de mudanças no campo político num contexto de crise inflacionária. Foi o primeiro a país a ter, por exigência do Fundo, metas de inflação como status de critério de desempenho (Berti, 1999). Em 1994, com as medidas de desindexação planejada da economia e o Plano Real, o cenário brasileiro permitia novas negociações com o Fundo e com os credores internacionais (Almeida, 2014; Berti, 1999).

O Plano Real buscou o controle da inflação a partir de estratégias distintas àquelas promovidas - sem grande sucesso - em planos anteriores: a abertura da economia ao mercado externo, mantendo a moeda brasileira quase que equiparada ao dólar americano; a utilização de 


\section{Revista \\ UNEMAT de \\ Contabilidade}

v. 9 , n. 17,2020

uma moeda de transição, a URV (Unidade Real de Valor); e a organização das contas públicas (Lopes, 2010). Assim verificou-se nos três anos consecutivos a sua implementação o crescimento do PIB de 4,2\% em 1995, de 2,7\% em 1996 e de 3,3\% em 1997 (LAMEIRA, 2004)

Em 1998 o FMI estabelece como uma das condições do acordo que fosse redigida uma lei de responsabilidade fiscal, que deveria versar sobre mudanças na gestão das finanças públicas: com um planejamento orçamentário e a previsão de medidas disciplinares para o descumprimento das metas e procedimentos definidos (Alves, Peliano e Coimbra, 1998). Em cumprimento a promessa ao Fundo, o então presidente, Fernando Henrique Cardoso, sanciona em maio de 2000 a Lei de Responsabilidade Fiscal (LRF)

Quanto a reformas tributárias, o acordo de 1998 definia a criação do Imposto sobre o Valor Adicionado Nacional (IVA Nacional), que substituiria alguns impostos de nível estadual e municipal e cuja receita seria dividida entre as três esferas de governo (ALVES, PELIANO E COIMBRA, 1998).

Em 2002, o governo brasileiro comprometeu-se a atingir e manter o nível do superávit primário em 3,75\% do PIB em 2003, mas o presidente Lula, quando assumiu em 2003, decidiu elevar a meta do superávit para 4,25\%. O mercado que antes apresentava desconfiança sobre a nova liderança brasileira, aprovou a conduta neoliberal do governo Lula. Além da meta fiscal, prometeu-se também reduzir os gastos e dívidas públicos; diminuir a burocracia e normas que atrapalhavam o empreendedorismo no país; realizar a reforma previdenciária; a reforma tributária; e sancionar uma lei de falências - sendo esta a única cumprida. Retornando ao sentimento de independência financeira presente no governo de JK, em 2005 as negociações com o FMI são interrompidas, sendo realizado um pagamento de mais de 14 bilhões de dólares (ALMEIDA, 2014).

Em 2010, o Brasil passa a ser credor do FMI, disponibilizando US\$ 10 bilhões. Mesmo passando por uma extensa fase de dependência, "o Brasil sempre relutou em mudar suas políticas domésticas por demanda do FMI, seja porque não queria descontinuar grandes planos de desenvolvimento seja porque pretendia lidar com programas de estabilização monetária sem se ater às recomendações mais ortodoxas do Fundo" (Almeida, 2014). A partir dos anos 2000, o Brasil persegue sua independência e, junto a outros países emergentes, investe seus esforços para aumentar seu poder nos processos decisórios da instituição (ALMEIDA, 2014; ITAMARATY, n.d.). 


\section{Revista

Em 2017, o Tesouro Nacional publica o relatório elaborado em 2016 pelo FMI sobre a transparência fiscal no Brasil. Neste relatório, o Fundo parabeniza a adoção gradual das IPSAS, destacando a relevância de se ter passado a adotar o regime de competência na contabilidade pública. Além disso, aponta expressamente para a adoção dos registros de concessão de contabilidade e das parcerias público-privadas nos termos da IPSAS 32 (Contratos de Concessão de Serviços Públicos: Concedente) (FMI, 2017).

"Nas últimas décadas, o Brasil melhorou consideravelmente a contabilidade pública

e a compilação das estatísticas fiscais. Com a adoção da LRF [sugerida pelo FMI], a apresentação de informações fiscais se tornou um ponto central das discussões sobre políticas fiscais e foram lançadas inúmeras iniciativas para aumentar a transparência e confiabilidade dos dados fiscais. $\mathrm{Na}$ área das contas públicas, a maioria dessas iniciativas está relacionada com a implementação gradual, desde 2008, de normas contábeis baseadas nas Normas Internacionais de Contabilidade Aplicadas ao Setor Público (IPSAS), o que permitiu às unidades do governo brasileiro produzir demonstrações financeiras com base no regime de competência cada vez mais abrangentes." (FMI, 2017)

\section{CONCLUSÃO}

$\mathrm{Na}$ busca de respostas para a inquietação dessa pesquisa utilizou-se a abordagem da Nova Sociologia Institucional, especificamente o conceito de isomorfismo (conhecido por ser um mecanismo de mudança estrutural aplicado numa instituição que passa a copiar práticas de outras instituições). Dentre as formas de isomorfismo, destaca-se o coercitivo, que se origina de pressões formais exercida por um agente externo que tem influência política sobre uma organização. Das evidências coletadas assume-se que o Fundo Monetário Internacional assume o papel de agente externo em relação ao governo brasileiro.

Também encontramos evidências de que o Brasil não está mais em posição de devedor no Fundo, ao contrário busca ampliar sua influência nas tomadas de decisão da agência. Apesar 


\section{Revista \\ UNEMAT de \\ Contabilidade}

v. 9 , n. 17,2020

de não haver uma relação de dependência financeira, pode-se observar uma influência política do FMI sobre o Brasil.

Ademais, o FMI, liderando a força tarefa para harmonização da contabilidade aplicada ao setor público (TFHPSA) organização que busca maneiras de reduzir as diferenças entre os relatórios contábeis e faz recomendações ao IPSASB, contribui grandemente para a elaboração do padrão internacional, ou seja, influência o processo de convergência diretamente no organismo normativo.

Cabe salientar que a Portaria emitida pelo regulador brasileiro não faz menção ao FMI em nenhum ponto, ao contrário cita as condições econômicas, a globalização e por fim a necessidade de demonstrações financeiras com números mais transparentes e que facilitem a responsabilização daqueles que tiveram uma gestão calamitosa.

Considerando o exposto, na pesquisa bibliográfica realizada encontramos evidências de que o FMI exerceu sobre o Brasil uma pressão coercitiva informal para que o governo adotasse o regime de competência e as IPSAS como um todo, a fim de que se aprimorasse a qualidade da informação contábil do setor público do país e de suas estatísticas fiscais.

Para pesquisas futuras, sugere-se que seja verificado - agregando à análise institucional, a teoria da dependência de recursos - a influência de outros atores externos para que o Brasil adotasse quase que integralmente as IPSAS. Quanto às limitações da pesquisa, pode-se elencar a reduzida produção nacional sobre a influência dos atores no processo de convergência às IPSAS.

Sugere-se ainda que se busque uma abordagem crítica e a fuga do positivismo; de modo que as pesquisas futuras possam contribuir significativamente para que o setor público produza uma informação contábil de qualidade sem que a adequação dos processos gere um ônus financeiro e um custo de oportunidade inadequados.

\section{REFERÊNCIA BIBLIOGRÁFICA}

Almeida, P. R. (2007). As relações econômicas internacionais do Brasil dos anos 1950 aos 80. Revista Brasileira de Política Internacional, 50(2), 60-79. 
Almeida, Paulo Roberto de. (2014). O Brasil e o FMI desde Bretton Woods: 70 anos de história. Revista Direito GV, 10(2), 469-496.

Alves, B., Peliano, J., Coimbra, M. (1998). Apresentação e Avaliação do Acordo do Governo do Brasil com o Fundo Monetário Internacional [pdf]. Retirado de http://www2.unifap.br/borges/files/2011/02/Apresenta\%C3\%A7\%C3\%A3o-eAvalia\%C3\%A7\%C3\%A3o-do-Acordo-do-Governo-do-Brasil-com-o-FMI.pdf

Barbosa Neto, J.; Colauto, R. (2010). Teoria Institucional: estudo bibliométrico em anais de congressos e periódicos científicos. ConTexto - Revista do Programa de Pós-Graduação em Controladoria e Contabilidade da UFRGS, p. 63-74. Retirado de https://seer.ufrgs.br/ConTexto/article/view/13372

Berti, S. (1999). O Brasil e o FMI nas décadas de 80 e 90: uma síntese das negociações. Trabalho de Conclusão de Curso de Graduação. Unicamp.

Biderman, C. Cozac, L., Rego, J. (1996). Conversas com economistas brasileiros. São Paulo: Editora 34

Borges, T. (2014) A nova contabilidade pública: contexto e desafios. Revista TCEMG, pp. 11 - 15. Retirado de https://revista1.tce.mg.gov.br/Content/Upload/Materia/2823.pdf

Brasil. Secretaria do Tesouro Nacional. PORTARIA N 510, DE 28 DE AGOSTO DE 2014. Dispõe sobre a instituição, as atribuições, a composição e o funcionamento do Grupo Técnico de Padronização de Procedimentos Contábeis - GTCON. Retirado de http://www.tesouro.fazenda.gov.br/documents/10180/372026/CPU_Portaria_STN_510_G TCON.PDF/0779f49f-6aea-439b-ba67-6224952c4f2a

Bresser, L. (1989). O Plano Verão e a Crise Estrutural da Economia Brasileira. Revista de Economia Política, pp. $124 \quad-\quad$ 136. Retirado de http://www.bresserpereira.org.br/documento/526

Burns, J.; Scapens, R. (2000). Conceptualizing management accounting change: an institutional framework. Management Accounting Research, v. 11, pp. 3-25. DOI: http://dx.doi.org/10.1006/mare.1999.0119 
Carpenter, V., Feroz, E. (1992). GAAP as a symbol of legitimacy: New York State's decision to adopt Generally Accepted Accounting Principles. Accounting, Organizations and Society, v. 17, n. 7 , pp. $613-643$

CFC. Conselho Federal de Contabilidade (2016). CFC publica a norma Estrutura Conceitual da contabilidade pública. Retirado de https://cfc.org.br/noticias/cfc-publica-a-norma-estruturaconceitual-da-contabilidade-publica/

Chan, J. (2010). As NICSPS e a contabilidade governamental de países em desenvolvimento. Repec, pp. 1 - 17. Retirado de http://www.repec.org.br/repec/article/view/145/72

Daft, R. L. Organizações: teoria e projetos. 11. ed. São Paulo: Cengage Learning, 2014.

Dias Filho, J., Machado, L. (2012). Abordagens da pesquisa em contabilidade. In: Lopes, A., Iudícibus, S. Teoria Avançada da Contabilidade. São Paulo: Atlas.

DiMaggio, P., \& Powell, W. (1983). The Iron Cage Revisited: Institutional Isomorphism and Collective Rationality in Organizational Fields. American Sociological Review, 48(2), 147 160. Retirado de http://www.jstor.org/stable/2095101

Fazenda, M. (2008). Portaria no 184 de 25 de agosto de 2008. (2008) Dispõe sobre as diretrizes a serem observadas no setor público (pelos entes públicos) quanto aos procedimentos, práticas, elaboração e divulgação das demonstrações contábeis, de forma a torná-los convergentes. de 26/08/08.

Figueiredo, L. M. (2017). Custo da regulação contábil no setor público brasileiro: aplicação do Standard Cost Model na adoção de IPSAS pelos ministérios federais. Dissertação de Mestrado, PPGCONT. Universidade de Brasília.

FMI. Fundo Monetário Internacional (n. d.). IMF Lending. Retirado de https://www.imf.org/en/About/Factsheets/IMF-Lending

. Fundo Monetário Internacional (n. d.). Lending by the IMF. Retirado de https://www.imf.org/external/about/lending.htm

Fundo Monetário Internacional (2017). Brasil: avaliação da transparência fiscal. Retirado de: 
http://www.tesouro.fazenda.gov.br/documents/10180/318974/Relat\%C3\%B3rio+de+transp ar\%C3\%AAncia+-+Portugu\%C3\%AAs/39be20dd-3846-4f8b-9dd4-429a207b8b68

Girotto, M. (2019) Entrevista: Andreas Bergmann, ex-chair do International Public Sector Accounting Standards Board (Ipsasb). Disponível em: https://cfc.org.br/noticias/entrevistaandreas-bergmann-ex-chair-do-international-public-sector-accounting-standards-boardipsasb/

(2017). Entrevista com Leonardo Silveira do Nascimento, Representante do Brasil no International Public Sector Accounting Standards Board (Ipsasb). Revista Brasileira de Contabilidade, $\quad$ pp. $\quad 5 \quad$ - $\quad 11 . \quad$ Retirado de http://rbc.cfc.org.br/index.php/rbc/article/view/1612/1143

Guarido Filho, E., Costa, M. (2012) Contabilidade e institucionalismo organizacional: fundamentos e implicações. Revista Contabilidade e Controladoria, v. 4, n. 1, pp. 20 - 41.

Guerreiro, R., Frezatti, F., Casado, T. (2006). Em busca de um melhor entendimento da contabilidade gerencial através da integração de conceitos da psicologia, cultura organizacional e teoria institucional. Revista de Contabilidade \& Finanças, pp. 7 - 21.

Hodgson, G. (2006). What are institutions? Journal of economic issues, v. 40(1), pp 1 - 25.

IBRACON (2017). O Brasil e as IPSAS. Normas internacionais trazem mais transparência à contabilidade pública. Revista transparência, p. 35. Retirado de http://www.ibracon.com.br/revistatransparencia/index.php?edicao=25

IFAC. International Federation of Accountants (2013). International Public Sector Accounting Standards (IPSASs) and Statistical Bases of Financial Reporting: An Analysis of Differences and Recommendations for Convergence [pdf]. Retirado de https://www.ifac.org/system/files/publications/files/international-public-sector.pdf

IPSASB. International Public Sector Accounting Standards Board (n.d.) About IPSASB. Retirado de https://www.ipsasb.org/about-ipsasb (acesso em 30/04/2019) 
Itamaraty (n.d.). Fundo Monetário Internacional. Retirado em http://www.itamaraty.gov.br/ptBR/politica-externa/diplomacia-economica-comercial-e-financeira/119-fundo-monetariointernacional

Lameira, Valdir de Jesus. (2004). Uma revisão sobre a economia brasileira e o mercado financeiro após o Plano Real: as mudanças e a evolução do mercado de capitais entre 1995 e 2002. Revista Contabilidade \& Finanças, 15(35), 96-110.

Lima, R. (2017). A influência dos atores no processo de convergência da Contabilidade Pública Brasileira aos padrões internacionais. Dissertação de Mestrado. Universidade de Brasília.

Lopes. T. (2010). A política do plano real estudada a partir da combinação da proposta Larida com o ajuste fiscal. Revista Análise, v. 21, n. 2, pp. 187 - 197. Retirado de http://revistaseletronicas.pucrs.br/ojs/index.php/face/article/viewFile/7569/6606

Machado-da-Silva, Clóvis L., Fonseca, Valéria Silva da, \& Crubellate, João Marcelo. (2005). Estrutura, agência e interpretação: elementos para uma abordagem recursiva do processo de institucionalização. Revista de Administração Contemporânea, 9(spe1), 9-39. DOI: https://dx.doi.org/10.1590/S1415-65552005000500002

Macêdo, J., Silva, J., Ribeiro Filho, J., Pederneiras, M., Feitosa, M. (2010). Convergência contábil na área pública: um a análise das percepções dos auditores de TCEs, contadores e gestores públicos. Revista de Contabilidade \& Organizações, v. 4, n. 8, p. 69-9.

Menezes Junior, C., Lima, D., Veiga, M., Prieto, M. (2016). Processo de convergência no setor público: análise comparativa entre os padrões contábeis da IFAC e do IASB. XIX SemeAd. Retirado de http://login.semead.com.br/19semead/arquivos/601.pdf

Mintzberg, H., Ahlstrand, B. \& Lampel, J. (2000). Safári de estratégia: um roteiro pela selva do planejamento estratégico. Bookman.

Mósca, H. (2006). Fatores Institucionais e Organizacionais que Afetam a Profissionalização da Gestão do Departamento de Futebol dos Clubes. Dissertação de Mestrado. PUC-Rio.

Nakagawa, M. (2007). Accountability: a razão de ser da contabilidade. Revista Contabilidade \& Finanças, 18(44), 7. https://dx.doi.org/10.1590/S1519-70772007000200001 
ONU. Organização das Nações Unidas (n. d.). FMI. Fundo Monetário Internacional. Retirado de https://nacoesunidas.org/agencia/fmi/

Oyadomari, J., Mendonça Neto, O., Cardoso, R., \& Lima, M. (2008). Fatores que influenciam a adoção de artefatos de controle gerencial nas empresas brasileiras: um estudo exploratório sob a ótica da teoria institucional. Revista De Contabilidade \& Organizações, 2(2), 55-70.

Peci, Alketa. (2006). A nova teoria institucional em estudos organizacionais: uma abordagem crítica. Cadernos EBAPE.BR, 4(1), 01-12. DOI: http://dx.doi.org/10.1590/S167939512006000100006

Schultz, G. (2016). Introdução à gestão de organizações (DERAD103). PLAGEDER.

Scott, WR e Meyer, JW (1994). Ambientes e organizações institucionais: complexidade estrutural e individualismo. Sábio.

Sasso, M. (2017). Adoção das normas de contabilidade oriundas do processo de convergência às IPSAS: respostas estratégicas de governos estaduais. Dissertação de Mestrado. Universidade de São Paulo.

Selznick, P (1972). A liderança na administração: uma interpretação sociológica. Rio de Janeiro: FGV.

Simões, A.; Rodrigues, J (2012). A abordagem da velha economia institucional na investigação em contabilidade e controlo de gestão contributos teóricos. RIGC - Vol. X, nº 19

STN. Secretaria do Tesouro Nacional (2017). Estrutura Conceitual da CASP - Elementos das Demonstrações Contábeis [PowerPoint presentation]. Retirado de https://www.tesouro.fazenda.gov.br/documents/10180/566752/M\%C3\%B3dulo+5++Estrutura+Conceital+-+Parte+II+-+Elementos.pdf/c9ab1fe0-d385-42b1-93fc$46 \mathrm{~cd} 7 \mathrm{~cd} 96293$

Secretaria do Tesouro Nacional (2017). Manual de Contabilidade Aplicada ao Setor Público. $8^{\mathrm{a}}$ ed. 
TCU. Tribunal de Contas da União (n. d.). Mecanismo de Accountability. Retirado de https://portal.tcu.gov.br/governanca/governanca-no-tcu/mecanismos-degovernanca/mecanismo-de-accountability.htm

Vásquez, A. S. (1992). Ética. Rio de Janeiro: Civilização Brasileira 